observations between ourselves and Dr Kay and his colleagues may be explicable by differences in the route of administration of monocrotaline and the size of the animals used. (ii) We find lung hyperplasia, right ventricular hypertrophy, and reductions in serotonin transport in the absence of changes in lung total ACE. (iii) If hyperplasia of an organ occurs, the expression of enzyme activities on a total organ basis is appropriate. (iv) We have observed right ventricular hypertrophy only after the development of lung hyperplasia. It is implied by Drs Keane and Kay that right ventricular hypertrophy may be obtained after monocrotaline administration in the absence of lung hyperplasia. This is an important statement, and should be appropriately documented (no data on organ weights are presented in their report), as it has a bearing on hypotheses concerning the inducement of hypertrophy.

RYAN J HUXTABLE

W MARK LAFRANCONI

Department of Pharmacology

University of Arizona

Health Sciences Center

Tucson, Arizona 85724

USA

' Huxtable R, Ciaramitaro D, Eisenstein D. The effect of a pyrrolizidine alkaloid, monocrotaline, and a pyrrole, dehydroretronecine, on the biochemical functions of the pulmonary endothelium. Mol Pharmacol 1978;14:1189-203.

${ }^{2}$ Kay JM, Heath D. Crotalaria spectabilis: the pulmonary hypertension plant. Springfield: Charles C Thomas, 1969.
Purulent pericarditis with tamponade: a rare complication of pectus repair

SIR,-Since the introduction of antibiotics purulent pericarditis has become uncommon and most cases occur after cardiac surgery. However, we have recently encountered such a case following surgery for pectus excavatum.

A 22 year old woman developed bilateral pleural effusions one month after classical repair of severe asymmetrical pectus excavatum. She also presented with clinical features of a right calf vein thrombosis. She was anticoagulated with heparin, but sustained a cardiorespiratory arrest 45 days after operation and was thought to have sustained a massive pulmonary embolism. When the chest was opened, however, the pericardium was found to contain a tense collection of pus. This was drained, with immediate improvement in the circulation. Her subsequent postoperative course was uneventful.

Occasional reports of purulent pericarditis following oesophageal perforation have appeared ${ }^{1}$ and on one occasion this presented as pericardial tamponade. ${ }^{2}$ Purulent pericarditis rarely occurs after surgery when the pericardium is not opened ${ }^{3}$ and to our knowledge this is the first report of pyogenic tamponade complicating repair of pectus excavatum.

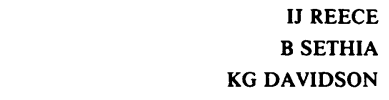

Department of Cardiac Surgery Royal Infirmary Glasgow G31 2ER

${ }^{1}$ Bozer AY, Saylam A, Ersoy U. Purulent pericarditis due to perforation of oesophagus with foreign body. J Thorac Cardiovasc Surg 1974;67:590-2.

${ }^{2}$ Welch TG, White TR, Lewis RP, Altieri PI, Vasko JS, Kilman JW Oesophagopericardial fistula presenting as cardiac tamponade. Chest 1972;62:728-31.

${ }^{3}$ Bulkley BN, Klacsmann PG, Hutchins GM. A clinicopathological study of post-thoracotomy purulent pericarditis. A continuing problem of diagnosis and therapy. $J$ Thorax Cardiovasc Surg 1977;73:408-12.

\title{
Notices
}

\section{British Thoracic Society}

7-9 May 1984

Joint Meeting with Australian Thoracic Society in Adelaide (meeting with chest physicians in Sydney 4 or 5 May)

4-6 July 1984

Brighton: Metropole Hotel (NB abstracts required by 19 April)

6-7 December 1984

London: Kensington Town Hall

3-5 July 1985

York University

\section{Correction}

Efiect of naloxone on circadian rhythm in lung function

We regret that in the paper by Dr S Al-Damluji and others (December 1983, pp914-8) there is an error in the caption $\mathbb{D}$ to table 2: "in five patients" should be "in six patients." 